\title{
THE STUDY OF THE FUNCTIONAL FEATURES OF THE SYNTHESIZED ALUMINUM-NICKEL-MOLYBDENUM HYDROTREATING CATALYSTS
}

\author{
Ozoda Abdullaevna Salikhova \\ Candidate of Technical Sciences, Associate Professor of the Department Organic Chemistry and Heavy \\ Organic Synthesis, Tashkent Institute of Chemical Technology, Tashkent, Uzbekistan.
}

\author{
Shakhzod Murodovich Makhmudov \\ Second Course Master Student, Department of Organic Chemistry and Heavy Organic Synthesis, \\ Tashkent Institute of Chemical Technology, Tashkent, Uzbekistan
}

\begin{abstract}
Miraziz Solikh ogli Zokirov
Second Course Master Student, Department of Organic Chemistry and Heavy Organic Synthesis, Tashkent Institute of Chemical Technology, Tashkent, Uzbekistan
\end{abstract}

Article DOI: https://doi.org/10.36713/epra4484

\begin{abstract}
The process of hydro-desulfurization of various mineral oils, which play a big role in the modern oil refining technology, continues to improve intensively and its value increases. Despite the fact that nowadays, hydro treating is one of the largest catalytic processes in the modern oil refining industry, the power of hydro desulfurization in the world is estimated as 950 million tons a year. So, it can be concluded that the study of hydro treating catalysts, the chemistry of hydrodesulfurization processes are the high priority tasks leading to the technological solving of the problem of hydro treating process. Moreover, it is also necessary to study other major issues related to the hydro treating process: study of the interaction between active metals and carriers; reactions in the solid phase as swell as issues of oxide reduction or their conversion to sulfides. The determination of the surface state in equilibrium conditions, the amount of the coke deposits, the stoichiometry of the catalysts, its changes during activation and regeneration during catalytic process. This article outlines the development of the production of highly active aluminum-nickel-molybdenum catalysts for hydro treating distillate raw materials, improving its physical and chemical properties and activity by modification of the carrier and by studying of the influence of activation conditions.
\end{abstract}

KEYWORDS: hydrogenation activity, sulfurization of Al-Ni-Mo catalyst, activity of the catalyst, thiophene hydrogenolysis.

\section{INTRODUCTION}

Nowadays the native hydrogenating catalysts, which are capable to provide a reduction of sulfur content in the refined gasoline (to 1,0 ) in diesel fuel up to $0,05 \%$ - are practically absent or are being developed. The development of highly effective and mechanically strong catalyst, instead of imported catalyst and establishing a correlation between physical and chemical properties of catalyst- is the main aim of this work.

The study of the functional features of catalysts has a great importance for synthesis of active and selective catalysts. The creation of catalysts with optimal combination of hydrogenating, isomerizing and splitting activity is required in order to ensure the high selectivity in hydro treatment process. One of the ways 
that determine the possibility of creating catalysts characterized by certain features is the study of chemism of conversion raw materials into them depending on the synthesis method, their composition and activation conditions during the chemical process. Activity, selectivity and stability of hydrotreating catalysts depend on the method of adding the catalyst in the process. This article is directed to the creation of highly effective hydro treating catalysts of materials in order to research the functional features of synthesized catalysts in the hydro treating mode, where was used a model mixture of benzene-thiophene $(0,05 \%)$, the chemism of catalyst formations of which is widely investigated. This allowed to judge about the synthesized catalysts in different reactions, occurring during the process of hydro treatment.

\section{MATERIALS AND METHODS}

The catalyst activity in hydrogenation and hydrogenolysis reactions of sulfur compounds, isomerization, splitting in the process - were investigated in this installation at constant technological parameters $\left(360^{\circ} \mathrm{C}\right)$, pressure $(5,0 \mathrm{MPa})$, volumetric speed of raw materials $(1,5$ hour -1$)$, hydrogen ratio is 800 , the duration of the experiment- 12 hours, loading of catalysts (grain $0,4-0,5 \mathrm{~mm}$ ) $10 \mathrm{~cm} 3$. Analysis of raw materials and catalysts were hold by using chromatographic method. The hydrogenating activity of the catalyst was estimated in relation to the sum of the amounts of methyl-cyclohexane, cleavage products to the amount of methyl cyclopentane.

The activity in the reaction of thiophene hydrogenolysis was evaluated by the residual content of thiophene sulfur in the catalyst, which is defined by photocolorimetric method. The study was carried out by comparison of the functional properties of catalysts with their physical and chemical characteristics: phase composition of the surface phase, determined by the photographic method, the specific surface, acidity, defined by method of high-temperature of pyridine adsorption and the acidity spectrum, which was estimated by the value of the energy value of activation of pyridine desorption. It is known that the most active are those catalysts, which contain metals and their compounds in the state of lower valences. The transfer of metal oxides from the highest valence state into lower valences often reduces the active surface of the catalyst, which should lead to the decrease in its activity. So, preliminary thermal processing of an aluminum-nickel-molybdenum catalyst in the hydrogen medium at the temperature $500^{\circ} \mathrm{C}$ reduces the active surface of nickel and molybdenum. However, prerestoration of catalyst can lead to the increase of hydrogenation activity and reduces the coke formation, therefore increases the stability of catalyst and the time of inter-regenerative mileage. On the other hand, the preliminary restoration and subsequent sulfurization of the Al-Ni-Mo of the catalyst increases its mechanical strength. Therefore, we can understand that there is no final representation of the catalyst at the stage of its activation. Consequently, the part of researches we conducted on catalysts, restored in the current of hydrogen.

\section{RESULTS AND DISCUSSION}

In the study of system $\mathrm{NiO}-\mathrm{MoO}_{3}$, it is shown that the optimal temperature at which the maximum surface of active phase is formed is $500^{\circ} \mathrm{C}$. For this reason, in our research were taken the temperature $500^{\circ} \mathrm{C}$ and $600^{\circ} \mathrm{C}$. In the table 1 is shown the comparative data by activity of binary compositions $\mathrm{NiO} / \mathrm{Al}_{2} \mathrm{O}_{3}(\mathrm{BF}-1)$ and $\mathrm{MoO}_{3} / \mathrm{Al}_{2} \mathrm{O}_{3}$ (BF-5), included in the composition of aluminum-nickel-molybdenum catalyst (BF-2), synthesized by traditional method. The activity was studied in the process of hydro treating the model mixture of carbon oil (benzene)- thiophene. The table shows the data at the end of the 12-hour cycle trials. Samples of catalysts were taken by co-deposition of aluminum hydroxide with aqueous solutions of nickel nitric acid salts and ammonium paromolybdate, drying at the temperature of $140^{\circ} \mathrm{C}$ during 4 hours and subsequent calcination at the temperature of $5000 \mathrm{C}$ and $600^{\circ} \mathrm{C}$. The data in the table 1 shows that the model BF$1\left(\mathrm{NiO}-4.0 ; \mathrm{Al}_{2} \mathrm{O}_{3}-96,0 \%\right)$ is characterized only by hydrogenating activity which quickly falls in the first hours of operation and at the end of the cycle is only insignificant value. The sample BF-5 $\left(\mathrm{MoO}_{3}-12,5\right.$; $\left.\mathrm{Al}_{2} \mathrm{O}_{3}-87,5 \%\right)$ after preliminary restoration shows the activity in hydrogenation and hydrogenolysis of thiophene. However, the activity of the catalyst in the hydrogenation reaction drops quickly and after 12 hours it is $4,5 \%-5,5 \%$. High activity in the reaction of thiophene hydrogenolysis is shown by the model BF-5 without preliminary reduction (Table 1), when the duration of the experiment increases, its hydrogenating activity increases 


\section{EPRA International Journal of Research and Development (IJRD)}

Volume: 5 | Issue: 5 | May 2020

- Peer Reviewed Journal

Table 1

Changes in the composition of the catalyzate on different catalysts depending on the reduce temperature

\begin{tabular}{|l|c|c|c|c|c|c|}
\hline \multicolumn{1}{|c|}{ Indicators } & $\begin{array}{c}\text { Sample } \\
\text { BF-1 }\end{array}$ & $\begin{array}{c}\text { Sample } \\
\text { BF-5 }\end{array}$ & $\begin{array}{c}\text { Sample } \\
\text { BF-5 }\end{array}$ & $\begin{array}{c}\text { Sample } \\
\text { BF-2 }\end{array}$ & $\begin{array}{c}\text { Sample } \\
\text { BF-2 }\end{array}$ & $\begin{array}{c}\text { Sample } \\
\text { BF-5 }\end{array}$ \\
\hline Calcination temperature, ${ }^{\circ} \mathrm{C}$ & 600 & 600 & 600 & 600 & 600 & 550 \\
\hline Calcination medium & air & air & air & air & air & air \\
\hline Reduce temperature, ${ }^{\circ} \mathrm{C}$ & 600 & 500 & 600 & 500 & 600 & 600 \\
\hline \multicolumn{7}{|c|}{ Composition of the catalyst, \% } \\
\hline $\mathrm{C}_{4}$ & - & - & - & 0,04 & 0,44 & 0,04 \\
\hline $\mathrm{C}_{5}$ & - & - & - & 0,12 & 1,96 & 0,04 \\
\hline $\mathrm{C}_{6}$ & - & - & - & 0,72 & 4,17 & 0,04 \\
\hline $\mathrm{MCP}$ & - & 0,20 & 0,1 & 2,38 & 3,19 & 0,06 \\
\hline $\mathrm{CH}$ & 0,98 & 5,41 & 4,5 & 96,21 & 86,67 & 39,4 \\
\hline $\mathrm{MCG}$ & - & - & - & - & - & - \\
\hline $\mathrm{C}_{6} \mathrm{H}_{6}$ & 99,02 & 94,39 & 95,4 & 0,54 & 0,57 & 60,5 \\
\hline $\begin{array}{l}\text { Sulfur content in the } \\
\text { catalyzate, ppm }\end{array}$ & 300 & 6 & 13 & 6 & 11 & 1 \\
\hline Deposits on catalyst; & & & & & & \\
\hline Carbon, \% & 0,5 & 0,51 & 0,57 & 0,18 & 0,22 & 0,16 \\
\hline Sulfur, \% & 0,25 & - & - & 0,06 & 0,08 & 0,06 \\
\hline Specific surface, $\mathrm{m}^{2} / \mathrm{g}$ & 167 & - & - & 169 & 140 & 200 \\
\hline
\end{tabular}

MCP-methyl cyclophentane, $C H$-cyclohexane, $M C G$ - methyl cyclohexane

The highest activity and stability of three catalysts is done by the sample BF-2 $\left(\mathrm{NiO}-4,0 ; \mathrm{MoO}_{3}-12,5\right.$; $\left.\mathrm{Al}_{2} \mathrm{O}_{3}-83,5 \%\right)$. In this catalyst, along with the hydrogenating reactions of thiophene hydrogenolysis, isomerization and cleavage reactions occur (Table1). When the restore temperature reduces from $600^{\circ} \mathrm{C}$ to $500^{\circ} \mathrm{C}$, the splitting activity of the catalyst decreases and

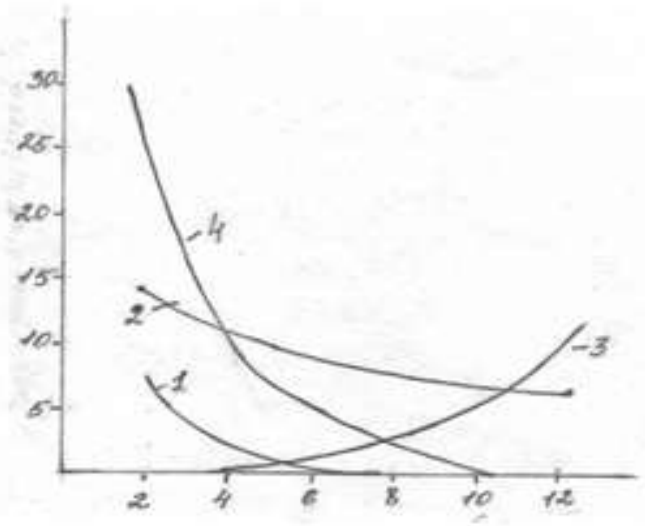

a) the hydrogenating activity increases. A significant influence on the activity of the catalyst is provided by the place, where it was calcined (air or nitrogen at the temperature of $600^{\circ} \mathrm{C}$ during 10 hours. It was found that the activity of the catalyst is higher after calcination in the air current.

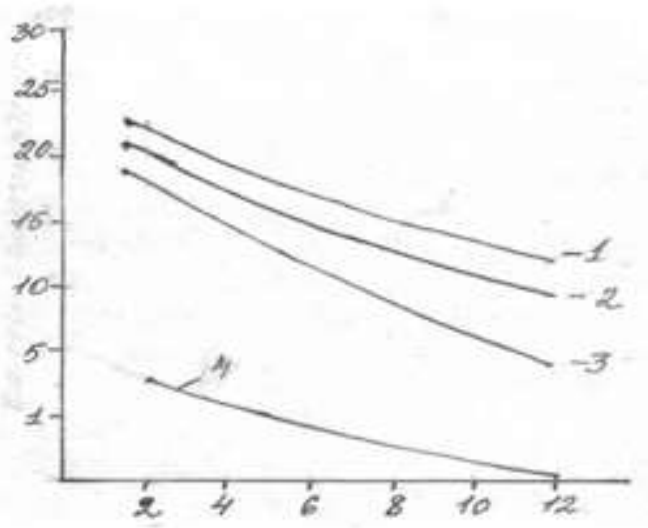

b)

Fig. 1. Changes in the activity of catalysts in the hydrogenation reaction(a) and hydrogenolysis of thiophene (b) 1-BF-1-calcined in the air, reduced $500^{\circ} \mathrm{C}, 2-\mathrm{BF}-5$-calcined in the air, reduced at the temperature $500{ }^{\circ} \mathrm{C}, 3-\mathrm{BF}-5$-calcined in the air without reduction; 4-BF-5-calcined in the nitrogen $\mathrm{N} 2$, reduced at the temperature $500{ }^{\circ} \mathrm{C}$.

The activity of samples BF-2 and BF-5 catalysts, reduced at the temperature of $500^{\circ} \mathrm{C}$ and $600^{\circ} \mathrm{C}$, the operating time decreases in hydrogenation reactions and increases in the reaction of thiophene hydrogenolysis (while operating time increases), the greatest activity in the reaction of thiophene hydrogenolysis shows the catalyst reduced at the temperature $500^{\circ} \mathrm{C}$, in contrast with the catalyst, reduced at the temperature $600^{\circ} \mathrm{C}$. The differences in activity can be explained by considering the possible chemical nature of the catalyst surface. 


\section{EPRA International Journal of Research and Development (IJRD)

Hydroxyl groups, which are always present on the surface of the alumina act like bronsted acid centers. In the process of calcination during dehydration from two neighboring $\mathrm{OH}$ groups, which make an electron deficit

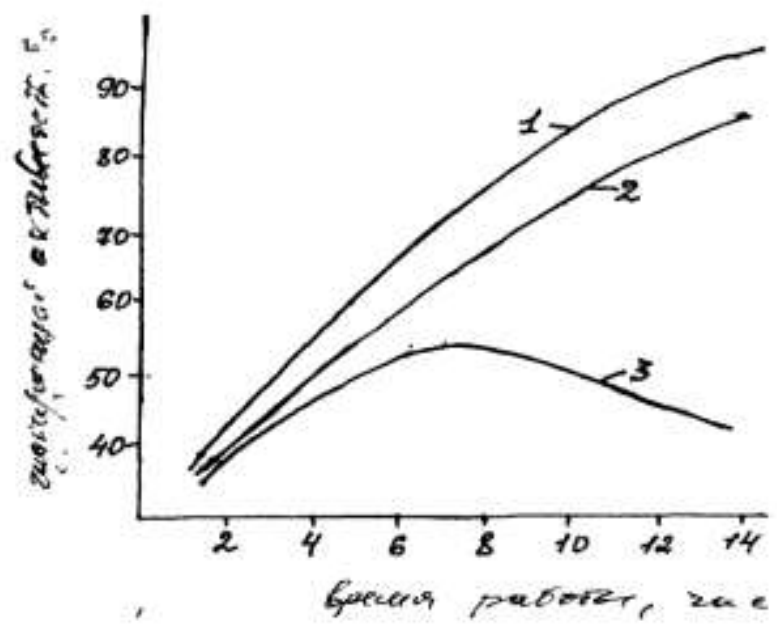

in one of the aluminum atoms, which act like a Lewis acid center.

Fig. 2. Changes in the activity in the hydrogenation reaction(a) and hydrogenolysis of thiophene(b) BF-2-calcined in the air, reduced at 500C; BF-2-calcined in the air, reduced at 600-C; BF-2-calcined in the nitrogen, reduced at $500{ }^{\circ} \mathrm{C}$.

Schematically this can be represented as follows:<smiles>OC[Al]O[Al]O[Al]</smiles>

The results of determination of the acidity of aluminum oxide, calcined at the temperature $600^{\circ} \mathrm{C} \mathrm{T}$ (table2), shows that the main part of pyridine is desorbed from the sample surface with an activation energy of $10-12 \mathrm{kcal} / \mathrm{mole}$ and only a small amount of pyridine $(0,016 \mathrm{~mole} / \mathrm{g})$, remaining on the surface after desorption at the temperature $350^{\circ} \mathrm{C}$, is characterized by the strength of binding is higher than $30 \mathrm{kcal} / \mathrm{mole}$ and caused by strong acidic centers. The presence of strong acid centers $\mathrm{Al}_{2} \mathrm{O}_{3}$ is probably connected with the presence of sulfate-ions, that are an admixture of aluminum oxide. Consequently, aluminum oxide surfaces are dominated by weak acid centers. The sample of the BF-1 ( $\left.\mathrm{NiO}-4.0 ; \mathrm{Al}_{2} \mathrm{O}_{3}-96,0 \%\right)$, obtained by co-precipitation after drying and calcination, has a solid solution of $\mathrm{NiO}-\mathrm{Al}_{2} \mathrm{O}_{3}$. It is possible that the surface centers can be formed by the following scheme:

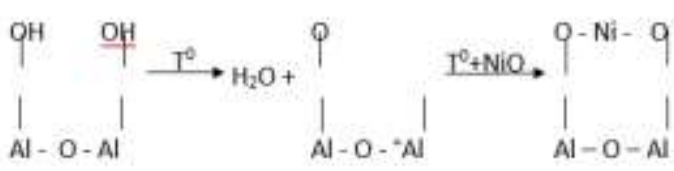

The reaction (2) should lead to decrease in acidity of the catalyst compared to aluminum oxide. However, when you enter nickel, the number of strong centers increases (Table 2). The increase of acidity of the sample BF-1, is obviously ion due to the fact that during calcination, a solid solution of $\mathrm{NiO}-\mathrm{Al}_{2} \mathrm{O}_{3}$ is mainly formed, where nickel is in octahedral or tetrahedral coordination, filling vacancies in the defective spinel structure of aluminum oxide, which leads to strengthening of electron-acceptor properties of the catalyst and therefore, the increase of acidity. When restoring the catalyst in the medium of the hydrogen in the surface layer, the nickel is reduced according to the scheme:
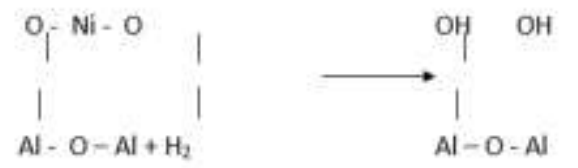

$+\mathrm{Ni}$

(3)

At the same time, the bronsted weak acid centers are regenerated, while the acidity of catalyst reduces (table 2).

Sulfurization of nickel on silica-alumina carrier leads to the reduction of acidity. 


\section{EPRA International Journal of Research and Development (IJRD)}

Volume: 5 | Issue: 5 | May 2020

- Peer Reviewed Journal

Table 2.

The dependence of acidity and activity of co-deposited catalysts on chemical composition

\begin{tabular}{|c|c|c|c|c|c|c|}
\hline Catalyst & $\begin{array}{c}\text { Acidity, } \\
\text { Mole/g }\end{array}$ & $\begin{array}{c}\text { Spectrum of } \\
\text { acid centers, } \\
\text { kkal/mole }\end{array}$ & $\begin{array}{c}\text { Hydrogenating } \\
\text { activity, \% }\end{array}$ & $\begin{array}{c}\text { Isomerizing } \\
\text { activity, \% }\end{array}$ & $\begin{array}{c}\text { Splitting } \\
\text { activity, \% }\end{array}$ & $\begin{array}{c}\text { Thiophene } \\
\text { conversion, } \\
\%\end{array}$ \\
\hline$\gamma-\mathrm{Al}_{2} \mathrm{O}_{3}$ & 0,016 & $\begin{array}{c}30 \\
10,9 \\
11,9\end{array}$ & - & - & - & - \\
\hline $\mathrm{BF}-1$ & 0,036 & $\begin{array}{c}30 \\
6,2\end{array}$ & 0,009 & - & - & 40,0 \\
\hline $\begin{array}{c}\mathrm{BF}-1 \\
\text { reduced } \\
500^{\circ} \mathrm{C}\end{array}$ & 0,009 & $\begin{array}{c}30 \\
9,7\end{array}$ & 0,097 & 0,024 & - & 96,5 \\
\hline $\mathrm{BF}-5$ & 0,12 & 30 & 0,097 & 0,024 & - & 96,5 \\
\hline
\end{tabular}

Comparing the data by the activity and acidity of catalyst BF-1, it can be concluded that only a small part of $\mathrm{Ni}$ can be in the free state, that participates in the benzol hydrogenation reaction. The hypothesis that nickel occupies free vacancies in the defective structure of aluminum oxide is confirmed by the data of investigation of the depth of sulfurizing catalysts. Sulfurization was hold in the current of hydrogen sulfide at the temperature of $380^{\circ} \mathrm{C}$. The amount of sulfur on the reduced and not reduced samples of BF-1 catalysts is the same and significantly less than stoichiometric one (2.4 weight, \% to nis). Low catalyst activity, stability to reducing and to the sulfurization say that nickel, which is in tetrahedral or octahedral coordination in a solid solution of nio- $\mathrm{Al}_{2} \mathrm{O}_{3}$, is catalytically inactive in the reactions of hydrogenation and hydrogenolysis of thiophene. According to the information of derivatographic research, during codeposition of aluminum hydroxide with ammonium paramolybdate, a solid solution of $\mathrm{MOO}_{3}-\mathrm{Al}_{2} \mathrm{O}_{3}$ is formed as it can be seen in the table 1 (sample BF-5), shows high activity in the reaction of thiophene hydrogen lysis. Derivatographic data studied also show that during calcination the sample BF-5 in the nitrogen medium, the concentration of MOo3 decreases in contrast with air calcination, the activity in the hydrogenolysis of thiophene reaction is also reduced. Therefore, the activity of the catalyst in this reaction is in the direct dependence on the concentration Moo3 in the solid solution. The intensive decline of hydrogenating activity in the first hours of operation is obviously explained by sulfurization of hydrogenating phase in the catalyst. It was found that aluminum oxide with applied molybdenum in the presence and absence of nickel, has acid centers of Bronsted and Lewis on its surface, which is defined by adsorption of pyridine by spectroscopic method. As a result, we can say that Mo on the surface of aluminum oxide is located in the tetrahedral and partially octahedral coordination, because during sulfurization, the sulfur should widen the coordinating sphere of molybdenum. As a result, the sulfur content in the sulfurized catalyst is less than it should be in $\operatorname{MOS}_{2}$ or in $\operatorname{MOs}_{3}$. The results obtained during studying the reducing and sulfurization of nio $/ \mathrm{Al}_{2} \mathrm{O}_{3}$ and $\mathrm{MOO}_{3} / \mathrm{Al}_{2} \mathrm{O}_{3}$ catalysts is close to the described model. The low degree of reduction says that the connection between nio and Moo are very strong due to the bridge formations of $\mathrm{Ni}-\mathrm{O}-\mathrm{Al}$ and $\mathrm{Mo}-\mathrm{O}-\mathrm{Al}$, the sulfurization occurs by connecting the sulfur to MOO4 or by substitution oxide ions to $\mathrm{MOO}_{6}$.

\section{CONCLUSION}

The development of technology for obtaining high active aluminum-nickel-molybdenum catalyst for hydro treating distillate types of raw material, improved its physical and chemical properties and activity by modifying the carrier, also the influence of activation conditions was studied.

\section{REFERENCES}

1. Hydrogenation processes in oil refining (Hydrocracking and hydro treating) retrospective annotated bibliographic index for 1988-1993. Moscow, 1994. pp. 60-65.

2. Akhmetov S.A. (2002). The technology of deep processing of oil and gas. Ufa, Gilem, $672 \mathrm{p}$.

3. Akhmedov D., Abidov B. A., Turobzhonov S.M. (2001). To the problem of creation of new catalysts for hydrogenating heavy petroleum fractions. The integration problems of undergraduates. Scientific thesis collection of Republic. T.2, Tashkent, $123 \mathrm{p}$. 